\title{
Acknowledgments
}

\section{Editors and Collaborators}

The collection of cases is edited by Per Pinstrup-Andersen, H.E. Babcock Professor of Food, Nutrition and Public Policy, Professor of Applied Economics and Management, and J. Thomas Clark Professor of Entrepreneurship, Cornell University and Fuzhi Cheng, Past Postdoctoral Fellow, Cornell University in collaboration with Søren E. Frandsen, Prorector, Aarhus University, Denmark, Arie Kuyvenhoven, Professor of Agricultural Economics, Wageningen University, The Netherlands, and Joachim von Braun, Director General, International Food Policy Research Institute (IFPRI), Washington, D.C. The case development was funded by the Cornell University Entrepreneurship Program, the H.E. Babcock Chair funds, Wageningen University, Copenhagen University, and IFPRI. Technical editing of the case studies was done by Heidi Fritschel and formatting by Patricia Mason.

\section{Advisory Task Force and Reviewers}

In order to help assure relevancy of the cases and the textbook to real policy situations and problems in developing countries, seven individuals from developing countries (two from each of Africa, Asia, and Latin America and one from the Former Soviet Union) form an advisory task force for the program. These individuals, who are university faculty members, high-level policy advisors, and former policy-makers, advise on all substantive aspects of the program, including the choice and content of cases and the content of the textbook.

The members of the Task Force are:

- Kwadwo Asenso-Okyere, Professor, Office of the Vice-Chancellor, University of Ghana

- Bernard Bashaasha, Head, Department of Agricultural Economics, Makerere University, Uganda

- Sattar Mandal, Professor, Department of Agricultural Economics, Bangladesh Agricultural University, Bangladesh

- Eugenia Serova, Professor, Institute for Transition Economics, Moscow, Russia

- Fernando Vio, Director, Institute of Nutrition, University of Chile, Chile

- Zhong Tang, Professor, School of Agricultural Economics and Rural Development, Renmin University, Beijing, China

- Ricardo Uauy, Professor, School of Public Health and Nutrition, University of Chile, Chile and Professor, London School of Hygiene and Tropical Medicine, University of London, United Kingdom.

All cases were peer reviewed. A list of reviewers is found on http:/ / cip.cornell.edu/gfs. 
